RETRACTION NOTE

\title{
Retraction Note: A novel microRNA identified in hepatocellular carcinomas is responsive to LEF1 and facilitates proliferation and epithelial-mesenchymal transition via targeting of NFIX
}

Yaqi Hu, Xu Guo, Jinxia Wang, Yankun Liu, Huijie Gao, Hongxia Fan, Xiangyang Nong, Xi Yang, Min Liu, Shengping Li and Hua Tang

(c) The Author(s) 2021

Oncogenesis (2021)10:51; https://doi.org/10.1038/s41389-021-00336-9

Retraction to: Oncogenesis https://doi.org/10.1038/s41389-0170010-x, published online 23 February 2018

The Editor-in-Chief has retracted this article because of significant concerns regarding a number of Figures presented in this work: Figures 3, 5 and 6 appear to contain multiple duplicated panels. The Editor-in-Chief therefore no longer has confidence in the integrity of the data in this article.

Yaqi Hu, Xu Guo, Jinxia Wang, Yankun Liu, Huijie Gao, Hongxia Fan, Xi Yang, Shengping $\mathrm{Li}$ and Hua Tang have agreed to this retraction; Xiangyang Nong and Min Liu have not responded to any correspondence from the Publisher about this retraction.

\begin{abstract}
(i) Open Access This article is licensed under a Creative Commons Attribution 4.0 International License, which permits use, sharing appropriate credit to the original author(s) and the source, provide a link to the Creative Commons license, and indicate if changes were made. The images or other third party material in this article are included in the article's Creative Commons license, unless indicated otherwise in a credit line to the material. If material is not included in the article's Creative Commons license and your intended use is not permitted by statutory regulation or exceeds the permitted use, you will need to obtain permission directly from the copyright holder. To view a copy of this license, visit http://creativecommons. org/licenses/by/4.0/.
\end{abstract}

(c) The Author(s) 2021 